......- CAPÍtULO 3

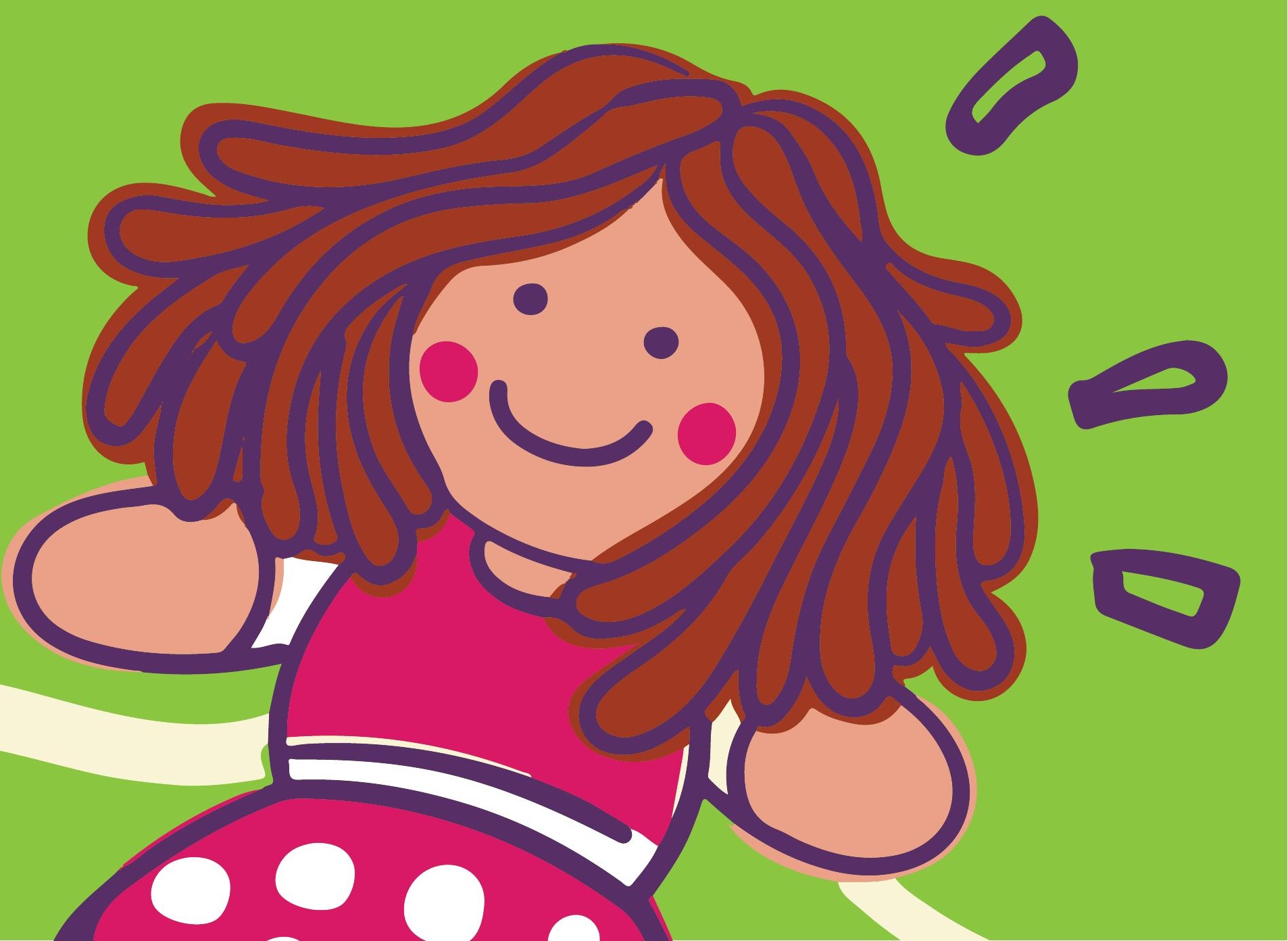




\section{Juego y ludotecas en el desarrollo de competencias ciudadanas, emocionales y de creatividad en niños: estableciendo}

\section{una línea base}

Iniciamos este capítulo con los resultados del primer momento del estudio longitudinal que se realizó durante cuatro años en distintas regiones de Colombia, cuyo propósito fue evaluar el impacto de las ludotecas en el desarrollo de competencias en niños. Este estuvo centrado en la comprensión del comportamiento de distintos tipos de competencias en la infancia: emocionales, ciudadanas y de creatividad, en un escenario concreto como el de las ludotecas, y en poder identificar el impacto que pueden producir estas en el desarrollo infantil.

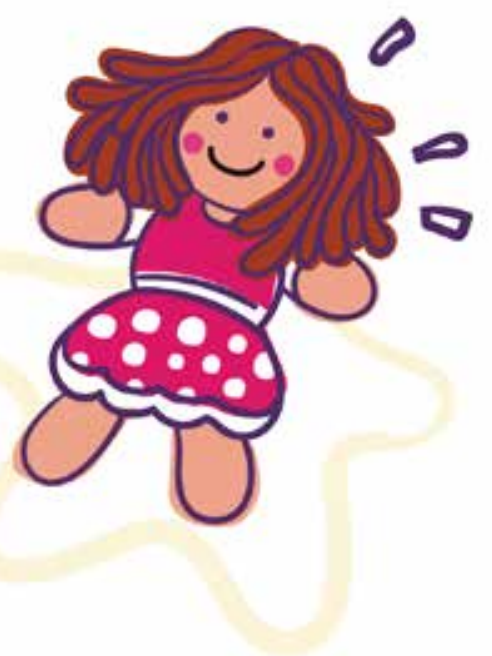




\section{Las competencias en la infancia}

Es importante iniciar comprendiendo el concepto de competencias. La competencia en la infancia hace referencia a un constructo amplio, el cual se vincula a una serie de conceptos que se relacionan con las capacidades, conocimientos, habilidades, destrezas y actitudes de los niños y niñas para actuar, de manera adaptativa, ante el medio, especialmente social, y bajo contextos ecológicos e históricos particulares, guardando relación estos con un desempeño adecuado durante el ciclo vital (Masten, 2006; Masten et al., 1995). Por ello, se considera un conjunto multidimensional que suele estar relacionado con el concepto de competencia social, en donde se incluye un repertorio amplio de capacidades y destrezas motoras, emocionales, del lenguaje, ciudadanas, entre otras. Estas guardan una relación importante con el desarrollo infantil en general, y juegan un papel clave en aspectos como la motivación o la toma de decisiones participativas (Fredricks \& Eccles, 2002), o con el desempeño posterior durante la adolescencia o la adultez temprana (Ireland, Sayers, Deere, Emond, \& Tobias, 2016; Kapeleris \& Paivio, 2011; Masten, Desjardins, McCormick, Kuo, \& Long, 2010; Shiner \& Masten, 2012). Dichas competencias parecen variar con el tiempo, y pueden tener ejecuciones distintas en razón al género (Fredricks \& Eccles, 2002; van der Wilt, van Kruistum, van der Veen, \& van Oers, 2015).

En Colombia, el concepto de competencias en la infancia se encuentra manifiesto en el "Documento 10", del Ministerio de Educación Nacional - MEN (2009). En este, las competencias se refieren a "capacidades generales que posibilitan los haceres, saberes y el poder hacer, que los niños manifiestan a lo largo de su desarrollo" (p.16). Guardan relación con los conocimientos de los niños para interactuar con los otros, con el entorno y con ellos mismos. Así, las competencias agencian y propician cambios hacia nuevos niveles de conocimiento. Para propósitos de este capítulo, nos interesa comprender lo que significan las competencias ciudadanas, emocionales y de creatividad en niños y niñas.Se 
entiende por competencias ciudadanas, "el conjunto de capacidades y habilidades cognitivas, emocionales y comunicativas -integradas- relacionadas con conocimientos básicos (contenidos, procedimientos, mecanismos), que orientan moral y políticamente nuestra acción ciudadana" (Ruiz \& Chaux, 2005, p.32). Dichas competencias hacen posible que el ciudadano actúe de manera constructiva en la sociedad democrática (Chaux, 2004). En la infancia, el desarrollo de esta competencia se vincula con la evolución de la comprensión de los derechos por parte del niño, con el alfabetismo político (political literacy) y con la participación infantil (Invernizzi \& Williams, 2008). Relacionado con esta competencia, para este estudio fue particularmente importante los conceptos asociados a la participación, la convivencia, la interacción en el juego, el manejo de conflictos y el manejo de reglas; estos son definidos de la siguiente manera:

Participación y Autonomía: de acuerdo con Moreno (2000), la participación de niños y niñas es definida como un proceso formativo, el cual les permite actuar autónomamente y esto fomenta y motiva el desarrollo de sus capacidades principalmente, con el fin de que los niños logren tener una participación activa tanto en su desarrollo como en la construcción de su entorno social, promoviendo una conciencia ciudadana.

Convivencia: siguiendo el planteamiento de Ortega (2006), este concepto hace referencia al reconocimiento de compartir diferentes escenarios y actividades siguiendo un conjunto de normas, con el fin de comprender los distintos puntos de vista de los demás y promover así un ambiente de solidaridad, autoestima, tolerancia, comprensión y respeto hacia sí mismo y hacia los otros.

Interacción en el juego: en el juego infantil, acorde con lo que Duek (2016) menciona, se construyen vínculos en diferentes ámbitos. Es por ello por lo que, por medio del juego, los niños configuran experiencias que les posibilitan desa- 
rrollar espacios de interacción y convivencia, conservando la característica del juego al ser una actividad lúdica, creativa y dinámica. Es una actividad específica en la que cada niño organiza su relación con el mismo, con otros niños y con su entorno social.

Manejo de conflictos: de acuerdo con Ochman y Escalante (2013), existen tres maneras diferentes de abordar el componente de manejo de conflictos: uno, es a partir de la aceptación del conflicto; otro, es analizando y considerando los elementos, causas y consecuencias del conflicto y, por último, por medio de la habilidad de negociación, diálogo y solución de conflictos.

Manejo de reglas: para Garoz-Puerta (2005), el juego cumple su función como una de las principales actividades de la etapa infantil. Entre otras razones, con el fin de brindar conocimiento y conciencia social. Este conocimiento y conciencia social los da el contexto, el cual a su vez está determinado por la cultura, y dicha cultura es la que establece una serie de reglas, cada una con un significado particular. Con esto, los niños por medio del juego aprenden a jugar, aprenden la importancia del cumplimiento y manejo de las reglas, también aprenden por qué son importantes las reglas para convivir en sociedad y, finalmente, aprenden y toman conciencia que su participación influye y tiene un impacto para la vida y para la interacción social.

Por su parte, se comprende por competencia emocional el conjunto de conocimientos, capacidades, habilidades y actitudes necesarias para conocer, expresar y regular de forma apropiada los fenómenos emocionales, en formas socialmente adecuadas, y la decodificación de estos procesos en sí mismos y en los otros (Bisquerra \& Pérez-Escoda, 2007; Pérez-Escoda, Velar, \& Ruiz-Bueno, 2014; Saarni, 1999). Esta permite comprender, interactuar y transformar el entorno; de ahí la importancia que adquiere en la interacción entre la persona y 

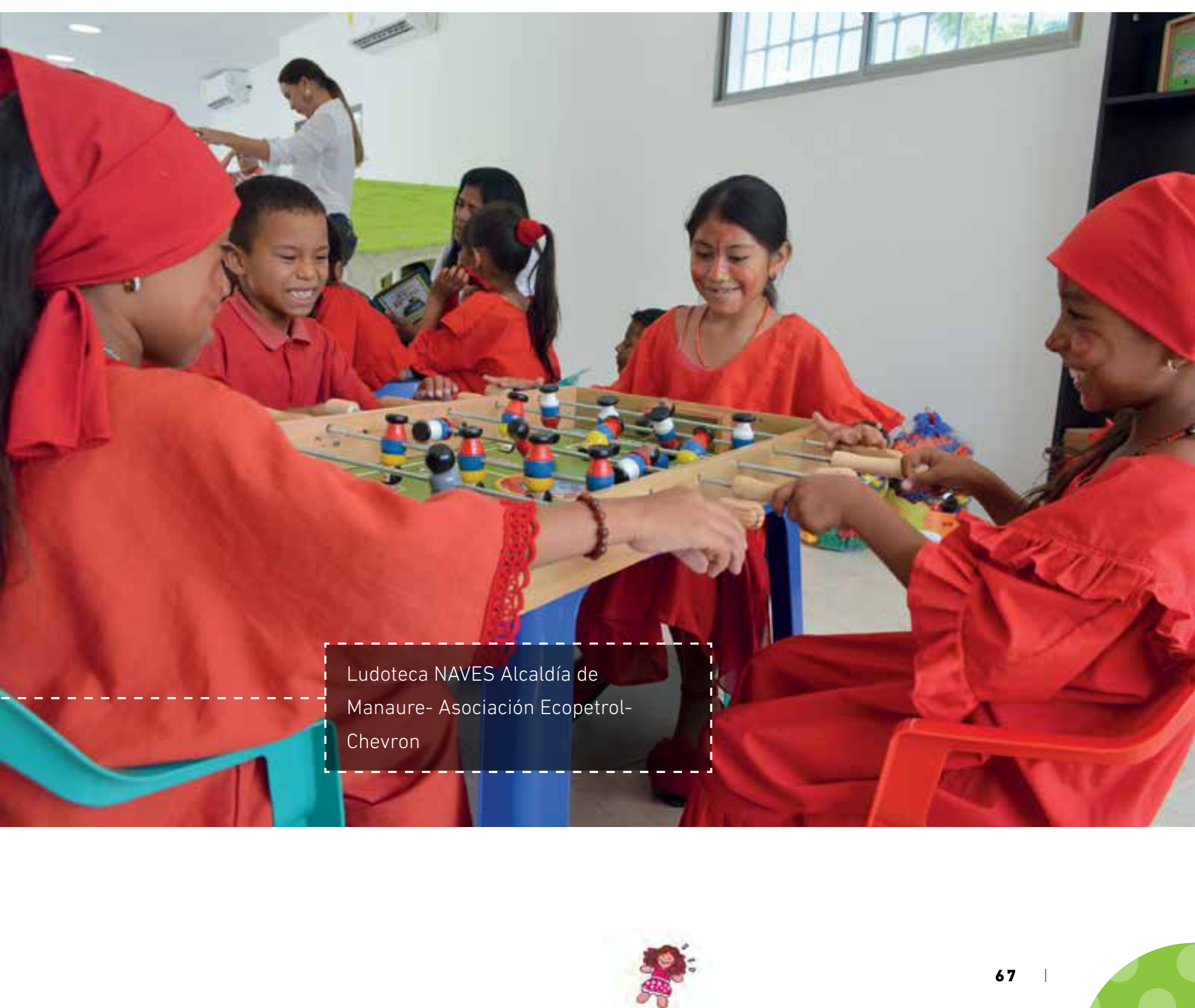
ambiente, y su papel en el aprendizaje (Gaeta \& López, 2013; Salazar \& Chiang, 2007). Diversos estudios han mostrado cómo componentes de esta competencia -como la regulación emocional- se convierten en vías para el desarrollo de la competencia social (Penela, Walker, Degnan, Fox, \& Henderson, 2015), o cómo esta guarda relación con el desarrollo del lenguaje en la infancia (Beck, Kumschick, Eid, \& Klann-Delius, 2012). En este estudio se tuvo en cuenta los conceptos de expresión de emociones, empatía y autorregulación emocional.

Expresión de emociones: la expresión de emociones se desarrolla gracias a la interpretación de la información proveniente de la observación de los rostros de las demás personas. Dicha información es integrada con los datos existentes en la memoria, así como las experiencias pasadas relacionadas con el conocimiento de las emociones (Salazar \& Chiang, 2007). Adicionalmente, según Fragoso-Luzuriaga (2015), esta capacidad es desarrollada gracias a las relaciones sociales desde una edad temprana. Estas interacciones facilitan la aparición de patrones afectivos que se hacen regulares y proporcionan la identificación de algunas emociones. Matsumoto, Hwang, López y Pérez-Nieto (2013), señalan que dicha capacidad se sigue ampliando en los años siguientes y en distintos contextos sociales, por ejemplo, con pares y amigos.

Según Riquelme, Munita, Jara y Montero (2013), en la etapa preescolar los niños tienen la capacidad de inferir emociones básicas a partir de la expresión facial y, de esta manera, interpretan las consecuencias de dichas emociones, permitiéndoles diferenciar las emociones propias de las de los demás. Sánchez-Aragón y Díaz-Loving (2009), señalan que los niños inicialmente tienden a reconocer mejor la alegría en comparación con expresiones de emociones negativas, por ejemplo, la tristeza y la rabia. Gradualmente, logran diferenciar las emociones negativas y son capaces de interpretar y entender el lenguaje emocional. Este proceso se puede asociar a la denominada alfabetización 
emocional (Matsumoto et al., 2013). Finalmente, Sánchez-Aragón y Díaz-Loving (2009), describen la expresión de emociones como la capacidad de manifestar emociones relacionadas con estados o situaciones personales; de este modo se busca influir en los estados de ánimo de las demás personas. La expresión de emociones se entiende como la habilidad para comunicar y compartir con los demás los pensamientos y sentimientos sobre diferentes eventos de la vida.

Empatía: López, Arán-Filippetti y Richaud (2014), mencionan que la empatía es uno de los componentes fundamentales para el desarrollo de vínculos sociales y de conductas prosociales; de esta forma, la empatía comienza a desarrollarse tempranamente. Los niños que están en la etapa preescolar serán capaces de desplegar mensajes emocionales no verbales, como son los abrazos o el gesto de fruncir el ceño, entre otros. Un componente fundamental en el desarrollo de la empatía es la congruencia emocional. Root y Denham (2010), señalan que este componente es el eje que provee el balance entre los pensamientos, las acciones y las emociones que se expresan y son sentidas. Alrededor de los 4 años los niños adquieren este componente, el cual les ayuda a comprender las emociones de otros, y a expresar y regular una gama más amplia de emociones. Por su parte, Denham (2007) define la empatía como la capacidad de comprender los sentimientos y emociones de los demás. Esta es considerada una habilidad indispensable para los seres humanos, teniendo en cuenta que toda nuestra vida transcurre en contextos sociales complejos. López et al. (2014), recalcan que, gracias a la naturaleza social de la humanidad, es esencial el reconocimiento y la comprensión de los estados emocionales de los demás.

Autorregulación: Rodríguez, Russián y Moreno (2009), definen la autorregulación como la habilidad de controlar las emociones en forma eficaz, generando homeostasis emocional y evitando respuestas impulsivas en situaciones de ira, provocación o miedo. En otras palabras, es percibir el propio estado afectivo 
sin dejarse afectar por él, de manera que no obstaculice el razonamiento y permita tomar decisiones acordes con los valores, normas sociales y culturales. Para Fayne, García, Montero y Valencia (2013)2007, las estrategias que los niños pequeños utilizan para regular sus emociones están en función de si se incrementa o si se disminuye el malestar emocional. Las estrategias que ellos utilizan están basadas en el cambio de atención, como distraerse, autocalmarse y buscar consuelo. Si el niño logra dirigir la atención lejos de la fuente del estrés, esto se asociará con un menor malestar emocional. Por otra parte, Rendón (2007) menciona que las conductas que intensifican la emoción, tales como la agresión y el llanto, mantienen la atención centrada en la fuente de malestar y dificultan las habilidades del niño para manejar el estrés y lidiar con las emociones.

La creatividad, por otro lado, es comprendida como la capacidad de utilizar la información y los conocimientos de forma nueva, de encontrar soluciones divergentes a los problemas, de inventar novedades eficientes y de generar ideas nuevas, apropiadas y de alta calidad (Donolo \& Elisondo, 2007). Se caracteriza por desempeños tanto de pensamiento racional, como por altos niveles de desarrollo emocional o de sentimientos, altos niveles de desarrollo físico y mental, y por altos niveles de conciencia (Saracho, 2002). En este estudio nos interesó conocer sobre pensamiento divergente, flexibilidad y elaboración, competencias definidas de la siguiente forma:

Pensamiento divergente: es la capacidad para producir un contenido que no solo es novedoso, original e inesperado sino, además, apropiado, útil y adaptado a la tarea en cuestión (UNESCO-OCDE, 2016). De acuerdo con Miguel Ángel Herrera (2004), es la posibilidad de dar diferentes soluciones a un mismo problema, es decir, de proponer diversas formas de llevar a cabo una actividad. 
Flexibilidad: esta competencia tiene que ver con la adaptación para cada momento (Lado, Ismach, \& Rossi, 2002). Implica provocar situaciones que permitan dichas adaptaciones a través de mediaciones (Ramírez, 2009). Se considera la flexibilidad como un elemento importante para el juego, junto con la espontaneidad y la versatilidad (Marín, 2009). Dicha flexibilidad permite estimular una actitud positiva en temas como la tolerancia, la cooperación, la coeducación, la solidaridad, entre otras (Santos \& Salgado, 2006).

Elaboración: relacionada con el pensamiento divergente y convergente, la elaboración hace referencia a la capacidad de planear de forma ordenada el desarrollo de una actividad, de manera creativa (Donolo \& Elisondo, 2007).

Diversas estrategias se han propuesto para el desarrollo de las competencias en la infancia, buena parte de estas en el escenario educativo, debido a que su evolución parece guardar relación con el éxito académico (Han, 2014) professional development (PD. Este último autor destaca, como motores del desarrollo de las competencias en el ambiente educativo, la retroalimentación de los procesos de aprendizaje, la reflexión constante o el reconocimiento de las necesidades contextuales de los niños.

\section{El lugar de las ludotecas en el desarrollo de competencias en la infancia}

Como escenario alternativo (o complementario) al escolar, aparecen las ludotecas. Diversos investigadores concuerdan en afirmar que estas son lugares ideales para potencializar competencias necesarias para el desarrollo integral y para facilitar la interacción entre pares (Kalinowski, 2010; Ochsner \& Gross, 2005; Ringoot et al., 2013). Así, las ludotecas pueden ser consideradas espacios únicos en donde se logran cambios individuales, familiares y sociales importantes (Nicholson, 2013). Según Managers (2005), las ludotecas promueven que el adulto 

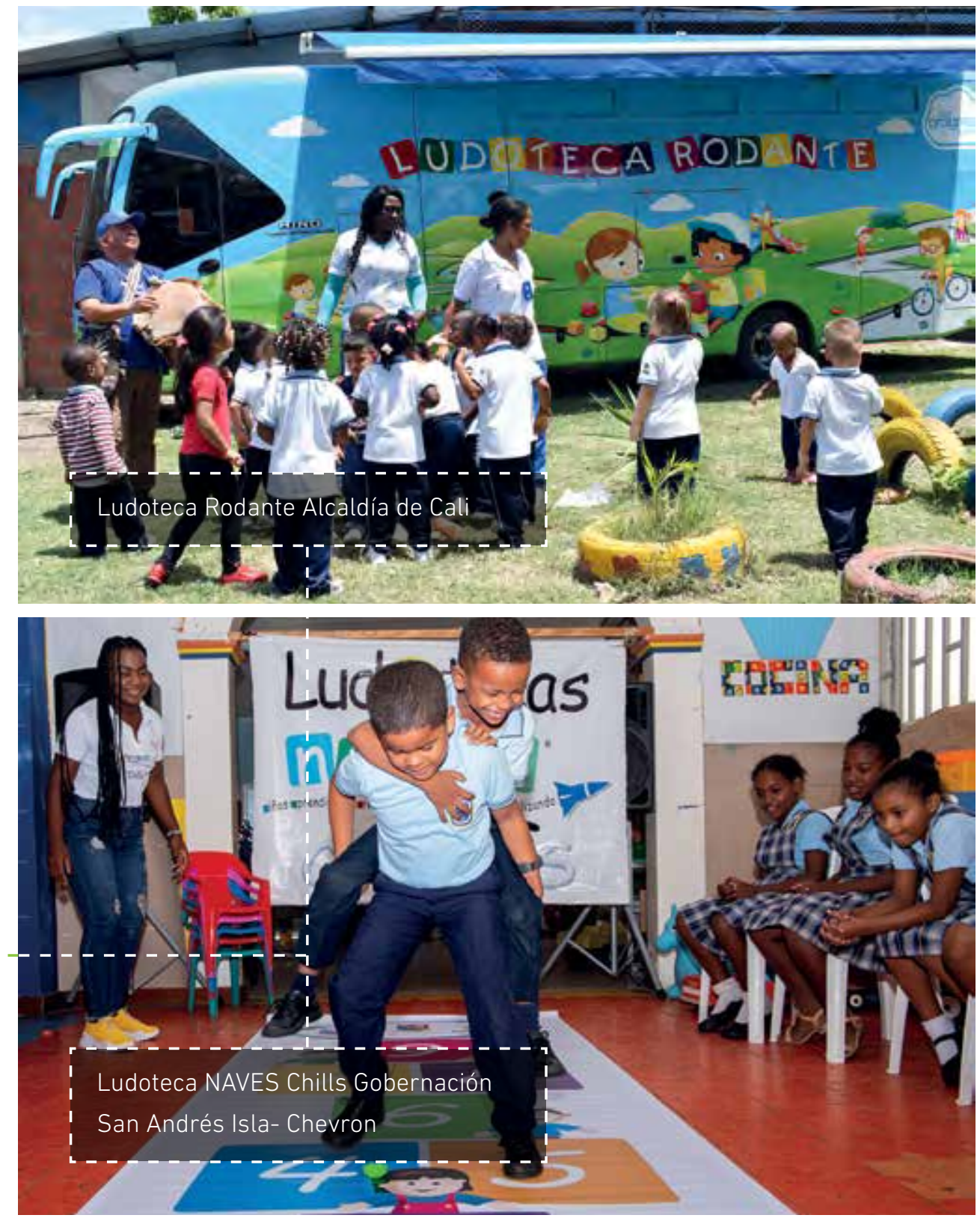

72

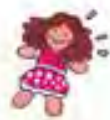


se comprometa en el juego con el niño, y realice un proceso de acompañamiento, fomentando así el desarrollo -en el infante- de la imaginación, la creatividad y la autonomía. Para este mismo autor, en ellas no solo se administran y prestan juguetes, sino que se interactúa con historias, cuentos y relatos, puesto que estas no son solo un lugar físico, sino también un espacio simbólico; es decir, son sitios de construcción de experiencias que facilitan el aprendizaje de los niños.

De acuerdo con Rosas et al. (2015), las ludotecas crean un espacio específico en el que el niño puede disfrutar del juego y de la interacción con sus pares, beneficiando así su desarrollo cognitivo, psicomotor y socioafectivo. En esta misma línea, según Reyes (2012), las ludotecas son aprovechadas como un recurso compensatorio que permite la participación de un amplio número de niños que se benefician de actividades de desarrollo global y de una intervención de carácter psicológico y social. De igual forma, Fleisher (2015), sostiene que en ellas se aprovecha el juego como un factor innato de aprendizaje, con el objetivo de desplegar una gama más amplia de habilidades, entre ellas, las emocionales. Es por ello por lo que las ludotecas posibilitan la interacción entre niños y adultos y, en general, entre el niño y la sociedad. Esta dinámica permite una perspectiva de mayor conciencia del mundo que rodea al niño (Corporación Día de la Niñez, 2009). Sin embargo, según Santos y Salgado (2006), el juego en las ludotecas, por sí solo, no es suficiente. Se requiere que la dinámica lúdica en estos escenarios se ciña a determinados objetivos, acompañados de una metodología bien estructurada, con el fin de contar con una orientación más apropiada. Esto marca una diferencia entre la ludoteca y otros espacios para el juego.

En Colombia, la incorporación de programas de ludotecas con carácter social ha tenido una historia reciente. Solo hasta 1998, por medio de la gestión de entidades públicas y privadas, y con el liderazgo de la Presidencia de la República de Colombia, se crea el programa de ludotecas NAVES (Niños y Niñas 
Aprendiendo, Viviendo, Experimentando y Socializando) que, como pocos en el país, ha conseguido sostenerse a lo largo del tiempo. Este programa está orientado a mejorar la calidad de vida de la población infantil más vulnerable a través de los escenarios lúdicos propuestos para los niños y sus familias (Corporación Día de la Niñez, 2009). Actualmente, funciona en las modalidades de ludotecas fijas e itinerantes en 149 municipios de Colombia, y atienden alrededor de 68.428 niños en todo el país (Corporación Juego y Niñez, 2017).

Si bien hasta acá se ha mencionado la importancia de las ludotecas en el desarrollo infantil, especialmente en el desarrollo motor, cognitivo, comunicativo, afectivo, moral y social, y en la facilitación de procesos de aprendizaje, aún son pocos los estudios que detallan estos efectos en estas dimensiones del desarrollo, y son menos los que hacen referencia a variables como la edad o el género. De encontrarse efectos positivos de estos escenarios en la infancia media o tardía en Colombia, es posible sugerir la incorporación de prácticas basadas en el juego o en las ludotecas en escenarios de educación primaria y secundaria, o la modificación de las políticas públicas locales para favorecer dichos escenarios y prácticas.

\section{Sobre este estudio}

Este estudio contó con la participación de 529 niños de seis municipios de Colombia; de estos, 247 eran niños (46.7\% de la muestra) y 282 niñas (53.3\%), con edades comprendidas entre el año y los 13 años ( $M=7.5$ años; $D E=1.89)$. Esta muestra se dividió en dos grupos: Uno de ellos estuvo conformado por 354 niños (167 niños y 187 niñas), que asistían a ludotecas; el otro, por 175 niños (80 niños y 95 niñas), que asistían regularmente a jardines infantiles o colegios de estas mismas ciudades. El criterio de selección de las ludotecas fue el tiempo de funcionamiento de esta (mayor a 2 años). Se actuó con las autoridades locales y ludotecarios de las distintas ciudades para ubicar la muestra de niños

\section{| $\mathbf{7 4}$}


del grupo comparación. La edad promedio de los niños que asistían a las ludotecas fue de 7.5 años ( $D E=2.07$ ) y la de los niños que no asistían fue de 7.4 años $(D E=1.45)$. No se encontraron diferencias significativas entre los grupos por edad $(t=1.01 ; p=.312)$ o género $\left(x^{2}=.10 ; p=.751\right)$. Dado que se trataba de menores de edad, para todos los casos se solicitó consentimiento informado de los padres, antes de las observaciones. Estas solicitudes se hicieron por medio de los directivos y maestros de los centros educativos y de los ludotecarios.

Luego de identificadas las ludotecas, jardines y colegios en los que se harían las observaciones, y luego de obtenidos los consentimientos de los padres, los observadores de campo (dos en cada ciudad), asistieron durante mes y medio a cada escenario de observación. Se realizaron observaciones de 15 niños durante una semana, ya fuese en la ludoteca, en colegios o jardines, dependiendo de la disponibilidad de los niños en las instituciones. Estas observaciones fueron repetidas durante la semana. Las observaciones se hicieron en parejas, como estrategia de triangulación de la información recabada. En promedio, se realizaron tres visitas por semana a cada institución, para tener consistencia en las valoraciones. Para esta investigación se diseñó un instrumento de observación dividido en las 3 dimensiones señaladas en la introducción: competencias ciudadanas, competencias emocionales y creatividad. Cada dimensión, a su vez, evaluaba distintos componentes: en la dimensión de competencia ciudadana se valoraba participación y autonomía (PA), convivencia (CV), interacción en el juego (IJ), manejo de conflictos (MC) y manejo de reglas (MR); en la dimensión de competencia emocional se valoraba la expresión de emociones (EE), empatía (EM) y autorregulación (AR); y en la dimensión de creatividad se valoraba pensamiento divergente (PD), flexibilidad (FX) y elaboración (EB) (ver Tabla 1 para distribución de componentes por dimensiones). Cada componente podía ser caracterizado en uno de cuatro niveles, que iban de un nivel bajo de expresión del componente (Valor 1), hasta un nivel alto (Valor 4). 


\section{DISTRIBUCIÓN DE COMPONENTES POR DIMENSIÓN}

\begin{tabular}{|c|c|c|c|}
\hline DIMENSIÓN & & VIATURA & COMPONENTE \\
\hline \multirow{5}{*}{ Competencia Ciudadana (CC) } & 1 & $P A$ & Participación y autonomía \\
\hline & 2 & CV & Convivencia \\
\hline & 3 & IJ & Interacción en el juego \\
\hline & 4 & $M C$ & Manejo de conflictos \\
\hline & 5 & $M R$ & Manejo de reglas \\
\hline \multirow{3}{*}{ Competencia Emocional (CE) } & 1 & $E E$ & Expresión de emociones \\
\hline & 2 & $E P$ & Empatía \\
\hline & 3 & $A R$ & Autorregulación \\
\hline \multirow{3}{*}{ Creatividad (CR) } & 1 & $P D$ & Pensamiento divergente \\
\hline & 2 & $F X$ & Flexibilidad \\
\hline & 3 & $E B$ & Elaboración \\
\hline
\end{tabular}

Además, el instrumento se diseñó para recoger información en dos situaciones distintas de observación: una, en un escenario de juego natural (espacio de descanso de los niños en ludoteca, jardín o colegio); y otra, en un escenario de juego en situación artificial (juego dirigido o propuesto por el observador). Si bien estos instrumentos tuvieron validación de contenido mediante jueces expertos, se realizó una evaluación de consistencia interna a través del estadístico de alfa de Cronbach tanto a la prueba general $(\alpha=.934)$ como al instrumento en cada situación: natural ( $\alpha=.890$ ) y artificial ( $\alpha=.877)$. De igual forma, se calculó la fiabilidad para cada dimensión (CC $\alpha=$.873; CE $\alpha=.809 ;$ CR $\alpha=.856$ ). A su vez, se quiso probar la consistencia de la prueba por medio de la evaluación del coeficiente de forma paralela entre las pruebas en situación natural y en situación 
artificial. El coeficiente de equivalencia, calculado mediante el coeficiente de correlación de Pearson, fue de $r_{\mathrm{g}}=.806$, y para cada dimensión fue de $r_{\mathrm{cc}}=.716$; $r_{c e}=.685 ;$ y $r_{c r}=.707$. Para todos los casos $p<.001$. Lo anterior señala la validez del instrumento utilizado.

La información fue recolectada y subida a una plataforma online diseñada para tal fin, desde la cual se conformó la base de datos para el análisis. Se utilizaron distintas estrategias estadísticas para las comparaciones, principalmente correlaciones con $r$ de Pearson, pruebas $t$ de diferencias de medias y ANOVA. Los análisis se realizaron utilizando el paquete de análisis estadístico para las ciencias sociales SPSS versión 23.

\section{Sobre los resultados del estudio en la línea base}

Si bien no era el propósito central de este estudio, se realizó una correlación entre los valores totales de las observaciones en cada competencia. Los análisis muestran que todas ellas encuentran relación entre sí: CC-CE $r=.685$; CC-CR $r=.814$; CE-CR $r=.650$. Para todos los casos $p<.001$.

Los análisis muestran diferencias entre los valores promedio de los grupos que asisten y que no asisten a ludotecas en cada una de las dimensiones evaluadas en la línea base: competencias ciudadanas (CC), emocionales (CE) y creatividad (CR). Para todos los casos, estos valores llegan a ser mayores en el grupo de niños que asiste a las ludotecas (ver Tabla 2). Una prueba t para muestras independientes señala diferencias significativas para competencias ciudadanas $\left(\Delta_{C C}=1.72 ; t=2.83 ; p=.005\right)$, y creatividad $\left(\Delta_{C R}=1.81 ; t=4.35\right.$; $p=.000)$. No se encontraron diferencias significativas, generales, para competencias emocionales $\left(\Delta_{\mathrm{CE}}=0.426 ; t=1.22 ; p=.221\right)$. 


\section{DESCRIPTIVOS GENERALES DEL DESEMPEÑO DE CADA GRUPO POR COMPETENCIA EN LA LÍNEA BASE}

\begin{tabular}{lcccccc}
\cline { 2 - 6 } & \multicolumn{5}{c}{ GRUPO } \\
\cline { 2 - 6 } & Media & $\begin{array}{c}\text { Desviación } \\
\text { estándar }\end{array}$ & $\begin{array}{c}\text { Media de error } \\
\text { estándar }\end{array}$ & Media & $\begin{array}{c}\text { Desviación } \\
\text { estándar }\end{array}$ & $\begin{array}{c}\text { Media de error } \\
\text { estándar }\end{array}$ \\
\cline { 2 - 6 } & 29.29 & 6.39 & 0.34 & 27.56 & 5.80 & 0.47 \\
\hline $\begin{array}{l}\text { Competencia } \\
\text { Ciudadana (CC) }\end{array}$ & 17.38 & 3.57 & 0.19 & 16.95 & 3.46 & 0.28 \\
\hline $\begin{array}{l}\text { Competencia } \\
\text { Emocional (CE) }\end{array}$ & 15.94 & 3.99 & 0.21 & 14.12 & 4.35 & 0.36 \\
\hline Creatividad (CR) & & & & & & \\
\hline
\end{tabular}

En la Tabla 3 se muestran las diferencias en cada una de las competencias ciudadanas entre el grupo de niños que asiste a las ludotecas y el grupo de niños que no asiste en la línea base. Las diferencias fueron significativas para los componentes de participación y autonomía $\left(\Delta_{\mathrm{PA}}=0.36 ; p=.02\right)$, convivencia $\left(\Delta_{\mathrm{CV}}=\right.$ 0.73; $p=.000)$, interacción en el juego $\left(\Delta_{\mathrm{IJ}}=0.23 ; p=.049\right)$, y manejo de reglas $\left(\Delta_{\mathrm{MR}}=0.37 ; p=.021\right)$. No se encontraron diferencias significativas para manejo de conflictos $\left(\triangle_{\mathrm{MC}}=0.03 ; p=.825\right)$. 


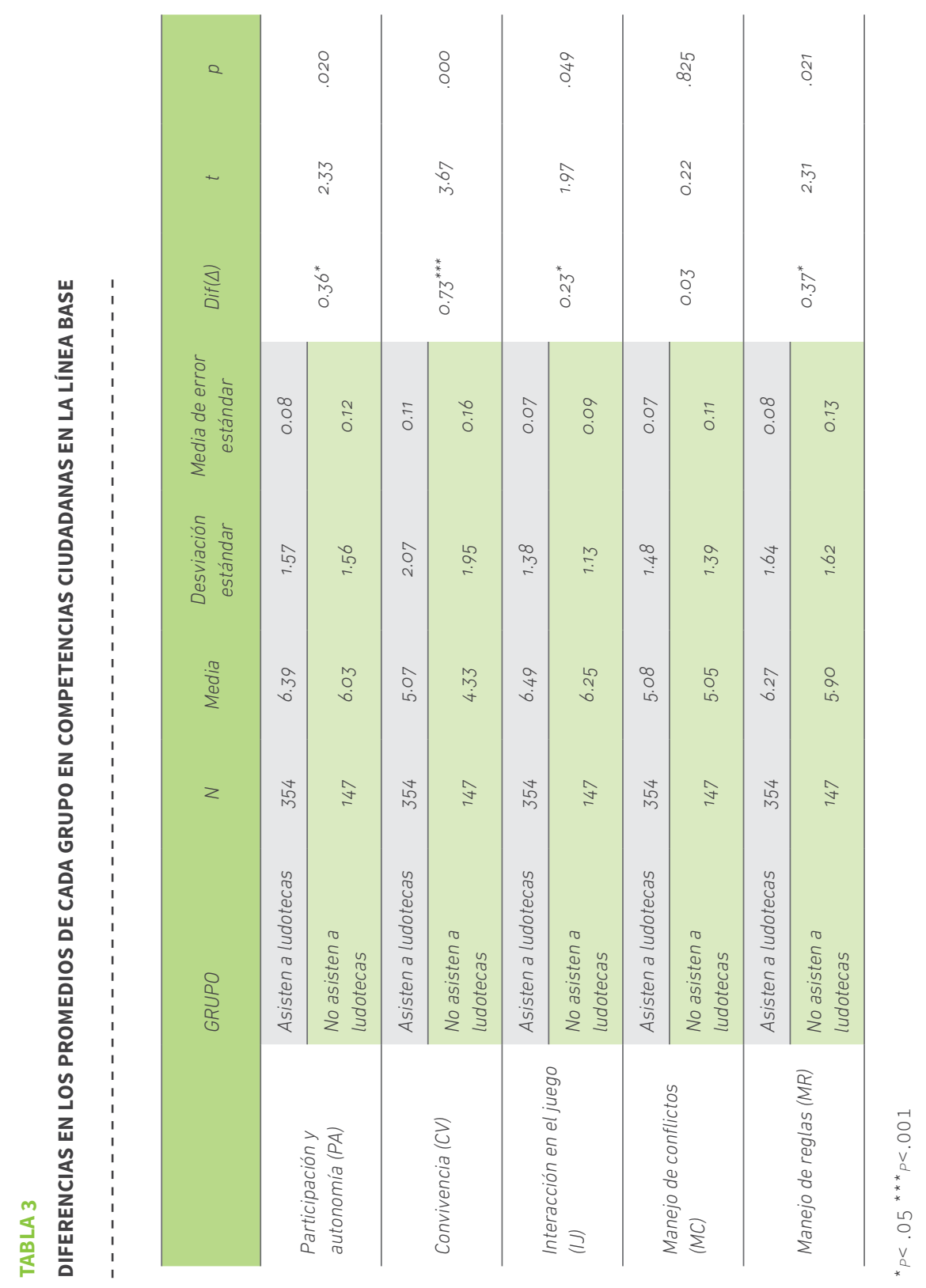


En la Tabla 4 se muestran las diferencias en cada una de las competencias emocionales entre el grupo de niños que asiste a las ludotecas y el grupo de niños que no asiste en la línea base. Las diferencias fueron significativas para los componentes de expresión de emociones $\left(\Delta_{\mathrm{EE}}=0.24 ; p=.05\right)$, y empatía $\left(\triangle_{\mathrm{EP}}=\right.$ 0.33; $p=.025)$. No se encontraron diferencias significativas para autorregulación $\left(\triangle_{\mathrm{AR}}=-0.15 ; p=.29\right)$.

TABLA 4

\section{DIFERENCIAS EN LOS PROMEDIOS DE CADA GRUPO EN COMPETENCIAS EMOCIONALES EN LA LÍNEA BASE}

\begin{tabular}{|c|c|c|c|c|c|c|c|c|}
\hline & GRUPO & $N$ & Media & $\begin{array}{c}\text { Desviación } \\
\text { estándar }\end{array}$ & $\begin{array}{c}\text { Media de error } \\
\text { estándar }\end{array}$ & $\operatorname{Dif}(\triangle)$ & $t$ & $p$ \\
\hline \multirow{2}{*}{$\begin{array}{l}\text { Expresión de } \\
\text { emociones (EE) }\end{array}$} & $\begin{array}{l}\text { Asisten a } \\
\text { ludotecas }\end{array}$ & 354 & 5.96 & 1.15 & 0.06 & \multirow{2}{*}{$0.24^{*}$} & \multirow{2}{*}{1.93} & \multirow{2}{*}{.050} \\
\hline & $\begin{array}{l}\text { No asisten a } \\
\text { ludotecas }\end{array}$ & 147 & 5.72 & 1.32 & 0.10 & & & \\
\hline \multirow{2}{*}{ Empatía (EP) } & $\begin{array}{l}\text { Asisten a } \\
\text { ludotecas }\end{array}$ & 354 & 5.53 & 1.51 & 0.08 & \multirow{2}{*}{$0.33^{*}$} & \multirow{2}{*}{2.25} & \multirow{2}{*}{.025} \\
\hline & $\begin{array}{l}\text { No asisten a } \\
\text { ludotecas }\end{array}$ & 147 & 5.20 & 1.54 & 0.12 & & & \\
\hline \multirow{2}{*}{$\begin{array}{l}\text { Autorregulación } \\
\text { (AR) }\end{array}$} & $\begin{array}{l}\text { Asisten a } \\
\text { ludotecas }\end{array}$ & 354 & 5.88 & 1.73 & 0.09 & \multirow{2}{*}{-0.15} & \multirow{2}{*}{-1.03} & \multirow{2}{*}{.29} \\
\hline & $\begin{array}{l}\text { No asisten a } \\
\text { ludotecas }\end{array}$ & 147 & 6.03 & 1.38 & 0.11 & & & \\
\hline
\end{tabular}

$*_{p<.05}$

En la Tabla 5 se muestran las diferencias en cada una de las competencias de creatividad entre el grupo de niños que asiste a las ludotecas y el grupo de niños que no asiste en la línea base. Las diferencias fueron significativas para los 
componentes de pensamiento divergente $\left(\triangle_{\mathrm{PD}}=0.85 ; p=.000\right)$, flexibilidad $\left(\triangle_{\mathrm{FX}}=\right.$ o.53; $p=.000)$ y elaboración $\left(\Delta_{\mathrm{EB}}=0.43 ; p=.003\right)$.

TABLA 5

\section{DIFERENCIAS EN LOS PROMEDIOS DE CADA GRUPO EN CREATIVIDAD EN LA LÍNEA BASE}

\begin{tabular}{|c|c|c|c|c|c|c|c|c|}
\hline & GRUPO & $N$ & Media & $\begin{array}{c}\text { Desviación } \\
\text { estándar }\end{array}$ & $\begin{array}{c}\text { Media de error } \\
\text { estándar }\end{array}$ & $\operatorname{Dif}(\Delta)$ & $t$ & $p$ \\
\hline \multirow{2}{*}{$\begin{array}{l}\text { Pensamiento } \\
\text { divergente (PD) }\end{array}$} & $\begin{array}{l}\text { Asisten a } \\
\text { ludotecas }\end{array}$ & 354 & 5.42 & 1.83 & 0.09 & \multirow{2}{*}{$0.85^{* * *}$} & \multirow{2}{*}{4.61} & \multirow{2}{*}{.000} \\
\hline & $\begin{array}{l}\text { No asisten a } \\
\text { ludotecas }\end{array}$ & 147 & 4.56 & 1.99 & 0.16 & & & \\
\hline \multirow{2}{*}{ Flexibilidad (FX) } & $\begin{array}{l}\text { Asisten a } \\
\text { ludotecas }\end{array}$ & 354 & 5.83 & 1.40 & 0.07 & \multirow{2}{*}{$0.53^{* * *}$} & \multirow{2}{*}{3.60} & \multirow{2}{*}{.000} \\
\hline & $\begin{array}{l}\text { No asisten a } \\
\text { ludotecas }\end{array}$ & 147 & 5.30 & 1.53 & 0.12 & & & \\
\hline \multirow{2}{*}{ Elaboración } & $\begin{array}{l}\text { Asisten a } \\
\text { ludotecas }\end{array}$ & 354 & 4.69 & 1.48 & 0.07 & \multirow{2}{*}{$0.43^{* *}$} & \multirow{2}{*}{2.97} & \multirow{2}{*}{.003} \\
\hline & $\begin{array}{l}\text { No asisten a } \\
\text { ludotecas }\end{array}$ & 147 & 4.26 & 1.53 & 0.12 & & & \\
\hline
\end{tabular}

${ }^{* *} p<.01{ }^{* * *} p<.001$

La figura 1 resume los perfiles de las competencias en los grupos que asisten y que no asisten a ludotecas. Se pueden observar picos altos para participación y autonomía, interacción en el juego y manejo de reglas, puntajes cercanos entres los grupos en manejo de conflictos y un puntaje superior del grupo comparación en autorregulación: 


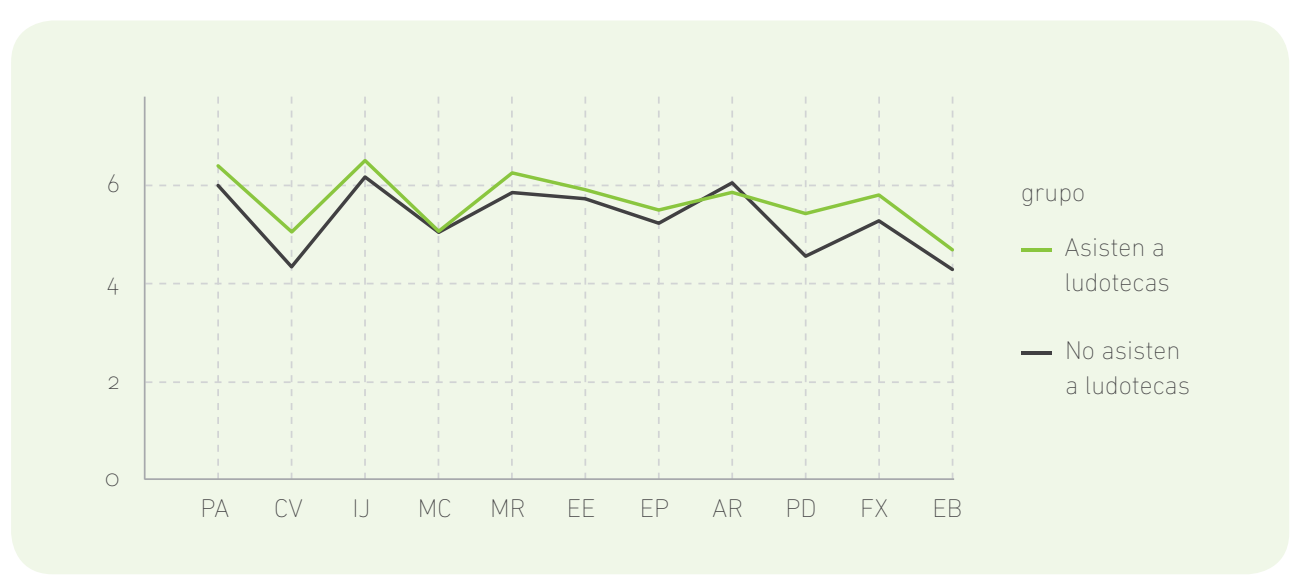

FIGURA 1. PERFILES DE LAS COMPETENCIAS EN GRUPOS DE NIÑOS QUE ASISTEN Y QUE NO ASISTEN A LUDOTECAS EN LA LÍNEA BASE

NOtA: PA=PARTICIPACIÓN Y AUTONOMÍA; CV=CONVIVENCIA; IJ=INTERACCIÓN EN EL JUEGO; MC=MANEJO DE CONFLICTOS; MR=MANEJo DE REGLAS; EE=EXPRESIÓN DE EMOCIONES; EP=EMPATía; AR=Autorregulación; PD=PenSAMIENTO DIVERgENTE; FX=FLEXIBILIDAD; EB=ELABORACIÓN.

En la Tabla 6 se puede observar que los niños que asisten a las ludotecas tienen, comparativamente con los niños que no asisten, en la línea base, mayores puntajes en convivencia $(\triangle C V=0.95 ; p=.002)$, manejo de reglas $(\triangle M R=0.58$; $p=.015)$, empatía $(\triangle \mathrm{EP}=0.53 ; p=.019)$, pensamiento divergente $(\triangle \mathrm{PD}=0.98$; $p=.000)$, flexibilidad $(\Delta \mathrm{FX}=0.74 ; p=.001)$ y elaboración $(\Delta \mathrm{EB}=0.6 ; p=.005)$. 


\section{DIFERENCIAS EN LOS PROMEDIOS DE PUNTAJES DE NIÑOS EN CADA COMPONENTE EN LA LÍNEA BASE}

\begin{tabular}{|c|c|c|c|c|c|c|c|c|}
\hline \multicolumn{2}{|c|}{ GRUPO } & $N$ & Media & $\begin{array}{c}\text { Desviación } \\
\text { estándar }\end{array}$ & $\begin{array}{c}\text { Media de error } \\
\text { estándar }\end{array}$ & $\operatorname{Dif}(\triangle)$ & $t$ & $p$ \\
\hline \multirow{2}{*}{$\begin{array}{l}\text { Participación y } \\
\text { autonomía (PA) }\end{array}$} & $\begin{array}{l}\text { Asisten a } \\
\text { ludotecas }\end{array}$ & 167 & 6.44 & 1.54 & 0.11 & \multirow{2}{*}{0.299} & \multirow{2}{*}{1.31} & \multirow{2}{*}{.190} \\
\hline & $\begin{array}{l}\text { No asisten a } \\
\text { ludotecas }\end{array}$ & 65 & 6.14 & 1.58 & 0.19 & & & \\
\hline \multirow{2}{*}{ Convivencia (CV) } & $\begin{array}{l}\text { Asisten a } \\
\text { ludotecas }\end{array}$ & 167 & 5.03 & 2.08 & 0.16 & \multirow{2}{*}{$0.953^{* *}$} & \multirow{2}{*}{3.16} & \multirow[b]{2}{*}{.002} \\
\hline & $\begin{array}{l}\text { No asisten a } \\
\text { ludotecas }\end{array}$ & 65 & 4.08 & 1.98 & 0.24 & & & \\
\hline \multirow{2}{*}{$\begin{array}{l}\text { Interacción en el } \\
\text { juego (IJ) }\end{array}$} & $\begin{array}{l}\text { Asisten a } \\
\text { ludotecas }\end{array}$ & 167 & 6.46 & 1.40 & 0.10 & \multirow{2}{*}{0.055} & \multirow{2}{*}{0.33} & \multirow{2}{*}{.740} \\
\hline & $\begin{array}{l}\text { No asisten a } \\
\text { ludotecas }\end{array}$ & 65 & 6.40 & 1.01 & 0.12 & & & \\
\hline \multirow{2}{*}{$\begin{array}{l}\text { Manejo de conflictos } \\
\text { (MC) }\end{array}$} & $\begin{array}{l}\text { Asisten a } \\
\text { ludotecas }\end{array}$ & 167 & 5.02 & 1.44 & 0.11 & \multirow{2}{*}{0.178} & \multirow{2}{*}{0.85} & \multirow{2}{*}{.394} \\
\hline & $\begin{array}{l}\text { No asisten a } \\
\text { ludotecas }\end{array}$ & 65 & 4.85 & 1.36 & 0.16 & & & \\
\hline \multirow{2}{*}{$\begin{array}{l}\text { Manejo de reglas } \\
\text { (MR) }\end{array}$} & $\begin{array}{l}\text { Asisten a } \\
\text { ludotecas }\end{array}$ & 167 & 6.46 & 1.60 & 0.12 & \multirow{2}{*}{$0.584^{*}$} & \multirow{2}{*}{2.45} & \multirow{2}{*}{.015} \\
\hline & $\begin{array}{l}\text { No asisten a } \\
\text { ludotecas }\end{array}$ & 65 & 5.88 & 1.67 & 0.20 & & & \\
\hline \multirow{2}{*}{$\begin{array}{l}\text { Expresión de } \\
\text { emociones (EE) }\end{array}$} & $\begin{array}{l}\text { Asisten a } \\
\text { ludotecas }\end{array}$ & 167 & 5.88 & 1.26 & 0.09 & \multirow{2}{*}{0.311} & \multirow{2}{*}{1.67} & \multirow{2}{*}{.095} \\
\hline & $\begin{array}{l}\text { No asisten a } \\
\text { ludotecas }\end{array}$ & 65 & 5.57 & 1.28 & 0.16 & & & \\
\hline
\end{tabular}


EL JUEGO: UN ASUNTO SERIO EN LA FORMACIÓN DE LOS NIÑOS Y LAS NIÑAS

\begin{tabular}{|c|c|c|c|c|c|c|c|c|}
\hline \multicolumn{2}{|c|}{ GRUPO } & $N$ & Media & Desviación & Media de error & $\operatorname{Dif}(\Delta)$ & $t$ & $p$ \\
\hline \multirow{2}{*}{ Empatía (EP) } & $\begin{array}{l}\text { Asisten a } \\
\text { ludotecas }\end{array}$ & 167 & 5.51 & 1.52 & 0.11 & \multirow{2}{*}{$0.530^{*}$} & \multirow{2}{*}{2.36} & \multirow{2}{*}{.019} \\
\hline & $\begin{array}{l}\text { No asisten a } \\
\text { ludotecas }\end{array}$ & 65 & 4.98 & 1.55 & 0.19 & & & \\
\hline \multirow{2}{*}{$\begin{array}{l}\text { Autorregulación } \\
\text { (AR) }\end{array}$} & $\begin{array}{l}\text { Asisten a } \\
\text { ludotecas }\end{array}$ & 167 & 5.82 & 1.85 & 0.14 & \multirow{2}{*}{-0.087} & \multirow{2}{*}{-0.39} & \multirow{2}{*}{.692} \\
\hline & $\begin{array}{l}\text { No asisten a } \\
\text { ludotecas }\end{array}$ & 65 & 5.91 & 1.34 & 0.16 & & & \\
\hline \multirow{2}{*}{$\begin{array}{l}\text { Pensamiento } \\
\text { divergente (PD) }\end{array}$} & $\begin{array}{l}\text { Asisten a } \\
\text { ludotecas }\end{array}$ & 167 & $5 \cdot 31$ & 1.84 & 0.14 & \multirow{2}{*}{$0.988^{* * *}$} & \multirow{2}{*}{3.57} & \multirow{2}{*}{.000} \\
\hline & $\begin{array}{l}\text { No asisten a } \\
\text { ludotecas }\end{array}$ & 65 & 4.32 & 2.00 & 0.24 & & & \\
\hline \multirow{2}{*}{ Flexibilidad (FX) } & $\begin{array}{l}\text { Asisten a } \\
\text { ludotecas }\end{array}$ & 167 & 5.88 & 1.35 & 0.10 & \multirow{2}{*}{$0.742^{* * *}$} & \multirow{2}{*}{3.30} & \multirow{2}{*}{.001} \\
\hline & $\begin{array}{l}\text { No asisten a } \\
\text { ludotecas }\end{array}$ & 65 & 5.14 & 1.60 & 0.19 & & & \\
\hline \multirow{2}{*}{ Elaboración (EB) } & $\begin{array}{l}\text { Asisten a } \\
\text { ludotecas }\end{array}$ & 167 & 4.62 & 1.46 & 0.11 & \multirow{2}{*}{$0.601^{* *}$} & \multirow{2}{*}{2.81} & \multirow{2}{*}{.005} \\
\hline & $\begin{array}{l}\text { No asisten a } \\
\text { ludotecas }\end{array}$ & 65 & 4.02 & 1.46 & 0.18 & & & \\
\hline
\end{tabular}

${ }^{\star} P<.05^{* \star} p<.01^{* * *} p<.001$

En la Tabla 7 se observa que las niñas que asisten a las ludotecas tienen, comparativamente con las niñas que no asisten, en la línea base, mayores puntajes en participación y autonomía $(\triangle P A=0.4 ; p=.05)$, convivencia $(\triangle C V=0.56$; $p=.036)$, interacción en el juego $(\Delta \mathrm{J}=0.37 ; p=.024)$ y pensamiento divergente $(\triangle \mathrm{PD}=0.75 ; p=.003)$. 


\section{DIFERENCIAS EN LOS PROMEDIOS DE PUNTAJES DE NIÑAS EN CADA COMPONENTE EN LA LÍNEA BASE}

\begin{tabular}{|c|c|c|c|c|c|c|c|c|}
\hline \multicolumn{2}{|c|}{ GRUPO } & $N$ & Media & $\begin{array}{c}\text { Desviación } \\
\text { estándar }\end{array}$ & $\begin{array}{c}\text { Media de error } \\
\text { estándar }\end{array}$ & $\operatorname{Dif}(\Delta)$ & $t$ & $p$ \\
\hline \multirow{2}{*}{$\begin{array}{l}\text { Participación y } \\
\text { autonomía (PA) }\end{array}$} & $\begin{array}{l}\text { Asisten a } \\
\text { ludotecas }\end{array}$ & 187 & 6.35 & 1.59 & 0.11 & \multirow{2}{*}{$0.402^{*}$} & \multirow{2}{*}{1.91} & \multirow{2}{*}{.05} \\
\hline & $\begin{array}{l}\text { No asisten a } \\
\text { ludotecas }\end{array}$ & 82 & 5.95 & 1.54 & 0.17 & & & \\
\hline \multirow{2}{*}{ Convivencia (CV) } & $\begin{array}{l}\text { Asisten a } \\
\text { ludotecas }\end{array}$ & 187 & 5.10 & 2.06 & 0.15 & \multirow{2}{*}{$0.565^{*}$} & \multirow{2}{*}{2.11} & \multirow{2}{*}{.036} \\
\hline & $\begin{array}{l}\text { No asisten a } \\
\text { ludotecas }\end{array}$ & 82 & 4.54 & 1.91 & 0.21 & & & \\
\hline \multirow{2}{*}{$\begin{array}{l}\text { Interacción en el } \\
\text { juego (IJ) }\end{array}$} & $\begin{array}{l}\text { Asisten a } \\
\text { ludotecas }\end{array}$ & 187 & 6.51 & 1.36 & 0.10 & \multirow{2}{*}{$0.379^{*}$} & \multirow{2}{*}{2.27} & \multirow{2}{*}{.024} \\
\hline & $\begin{array}{l}\text { No asisten a } \\
\text { ludotecas }\end{array}$ & 82 & 6.13 & 1.20 & 0.13 & & & \\
\hline \multirow{2}{*}{$\begin{array}{l}\text { Manejo de } \\
\text { conflictos (MC) }\end{array}$} & $\begin{array}{l}\text { Asisten a } \\
\text { ludotecas }\end{array}$ & 187 & 5.13 & 1.50 & 0.11 & \multirow{2}{*}{-0.079} & \multirow{2}{*}{-0.40} & \multirow{2}{*}{.686} \\
\hline & $\begin{array}{l}\text { No asisten a } \\
\text { ludotecas }\end{array}$ & 82 & 5.21 & 1.40 & 0.15 & & & \\
\hline \multirow{2}{*}{$\begin{array}{l}\text { Manejo de reglas } \\
\text { (MR) }\end{array}$} & $\begin{array}{l}\text { Asisten a } \\
\text { ludotecas }\end{array}$ & 187 & 6.10 & 1.65 & 0.12 & \multirow{2}{*}{0.182} & \multirow{2}{*}{0.84} & \multirow{2}{*}{.401} \\
\hline & $\begin{array}{l}\text { No asisten a } \\
\text { ludotecas }\end{array}$ & 82 & 5.91 & 1.58 & 0.17 & & & \\
\hline \multirow{2}{*}{$\begin{array}{l}\text { Expresión de } \\
\text { emociones (EE) }\end{array}$} & $\begin{array}{l}\text { Asisten a } \\
\text { ludotecas }\end{array}$ & 187 & 6.04 & 1.04 & 0.07 & \multirow{2}{*}{0.196} & \multirow{2}{*}{1.17} & \multirow{2}{*}{.244} \\
\hline & $\begin{array}{l}\text { No asisten a } \\
\text { ludotecas }\end{array}$ & 82 & 5.84 & 1.34 & 0.14 & & & \\
\hline
\end{tabular}




\begin{tabular}{|c|c|c|c|c|c|c|c|c|}
\hline \multicolumn{2}{|c|}{ GRUPO } & \multirow{2}{*}{$\begin{array}{c}N \\
187\end{array}$} & \multirow{2}{*}{$\begin{array}{l}\text { Media } \\
5.55\end{array}$} & \multirow{2}{*}{$\begin{array}{c}\text { Desviación } \\
\text { estándar } \\
1.50\end{array}$} & \multirow{2}{*}{$\begin{array}{c}\text { Media de error } \\
\text { estándar } \\
0.11\end{array}$} & \multirow{3}{*}{$\begin{array}{l}\operatorname{Dif}(\Delta) \\
0.185\end{array}$} & \multirow{3}{*}{$\begin{array}{c}t \\
0.92\end{array}$} & \multirow{3}{*}{$\begin{array}{c}p \\
.356\end{array}$} \\
\hline \multirow{2}{*}{ Empatía (EP) } & $\begin{array}{l}\text { Asisten a } \\
\text { ludotecas }\end{array}$ & & & & & & & \\
\hline & $\begin{array}{l}\text { No asisten a } \\
\text { ludotecas }\end{array}$ & 82 & $5 \cdot 37$ & 1.52 & 0.16 & & & \\
\hline \multirow{2}{*}{$\begin{array}{l}\text { Autorregulación } \\
(A R)\end{array}$} & $\begin{array}{l}\text { Asisten a } \\
\text { ludotecas }\end{array}$ & 187 & 5.94 & 1.61 & 0.11 & \multirow{2}{*}{-0.198} & \multirow{2}{*}{-1.00} & \multirow{2}{*}{.314} \\
\hline & $\begin{array}{l}\text { No asisten a } \\
\text { ludotecas }\end{array}$ & 82 & 6.13 & 1.42 & 0.15 & & & \\
\hline \multirow{2}{*}{$\begin{array}{l}\text { Pensamiento } \\
\text { divergente (PD) }\end{array}$} & $\begin{array}{l}\text { Asisten a } \\
\text { ludotecas }\end{array}$ & 187 & 5.51 & 1.83 & 0.13 & \multirow{2}{*}{$0.757^{* *}$} & \multirow{2}{*}{3.04} & \multirow{2}{*}{.003} \\
\hline & $\begin{array}{l}\text { No asisten a } \\
\text { ludotecas }\end{array}$ & 82 & 4.76 & 1.97 & 0.21 & & & \\
\hline \multirow{2}{*}{ Flexibilidad (FX) } & $\begin{array}{l}\text { Asisten a } \\
\text { ludotecas }\end{array}$ & 187 & 5.78 & 1.44 & 0.10 & \multirow{2}{*}{0.354} & \multirow{2}{*}{1.83} & \multirow{2}{*}{.068} \\
\hline & $\begin{array}{l}\text { No asisten a } \\
\text { ludotecas }\end{array}$ & 82 & 5.43 & 1.47 & 0.16 & & & \\
\hline \multirow{2}{*}{ Elaboración (EB) } & $\begin{array}{l}\text { Asisten a } \\
\text { ludotecas }\end{array}$ & 187 & 4.76 & 1.49 & 0.10 & \multirow{2}{*}{0.313} & \multirow{2}{*}{1.56} & \multirow{2}{*}{.120} \\
\hline & $\begin{array}{l}\text { No asisten a } \\
\text { ludotecas }\end{array}$ & 82 & 4.45 & 1.56 & 0.17 & & & \\
\hline
\end{tabular}

${ }^{*} P<.05{ }^{* \star} P<.01$

Para identificar la existencia de posibles diferencias por competencias entre rangos de edad (menores de 6 años, de 6 a 9 años y mayores de 9 años), se realizó un ANOVA de un factor. Este, en sentido general, muestra diferencias por edad en competencias ciudadanas y creatividad (Tabla 8): 


\begin{tabular}{lccc}
\hline COMPETENCIA & $G L$ & $F$ & $P$ \\
\hline Ciudadana (CC) & $(2,351)$ & 5.690 & .004 \\
\hline Emocional (CE) & $(2,351)$ & 2.072 & .128 \\
\hline Creatividad (CR) & $(2,351)$ & 5.746 & .004 \\
\hline
\end{tabular}

Dado que los valores de $F$ fueron significativos para competencia ciudadanas y creatividad $(p<.01)$, se realizó una prueba post hoc de Bonferroni, encontrándose diferencias significativas en CC entre el grupo de niños menores de 6 años $(M=27.32)$ y el grupo de niños de 6 a 9 años $(M=29.69 ; p=.012)$, y entre los menores de 6 años y los mayores de $9(M=30.77 ; p=.009)$. No se encontraron diferencias significativas entre el grupo de niños de entre 6 y 9 años y los de más de 9 años $(p=.872)$. Para CR las diferencias se establecieron entre el grupo de niños menores de 6 años $(M=15.04)$ y los mayores de 9 años $(M=17.49 ; p=.002)$, y entre el grupo de niños de 6 a 9 años $(M=15.94)$, y los mayores de 9 años $(p=.045)$. No se encontraron diferencias significativas en los puntajes entre los niños menores de 6 años y el grupo de niños de 6 a 9 años $(p=.232)$. A continuación, se presenta gráficamente los desempeños por cada competencia para el grupo de niños que asiste a ludotecas.

En el grupo de niños no intervenidos, el ANOVA solo muestra diferencias por grupo de edad en creatividad, tendiendo a disminuir todas las competencias después de los 6 años (ver tabla 12). La prueba post hoc de Bonferroni en CR solo muestra diferencias entre los niños menores de 6 años $(M=16.86)$, y el grupo de niños de 6 a 9 años $(M=13.83 ; p=.041)$. A continuación, se presenta gráficamente los desempeños por cada competencia para el grupo de niños que no asiste a ludotecas. 


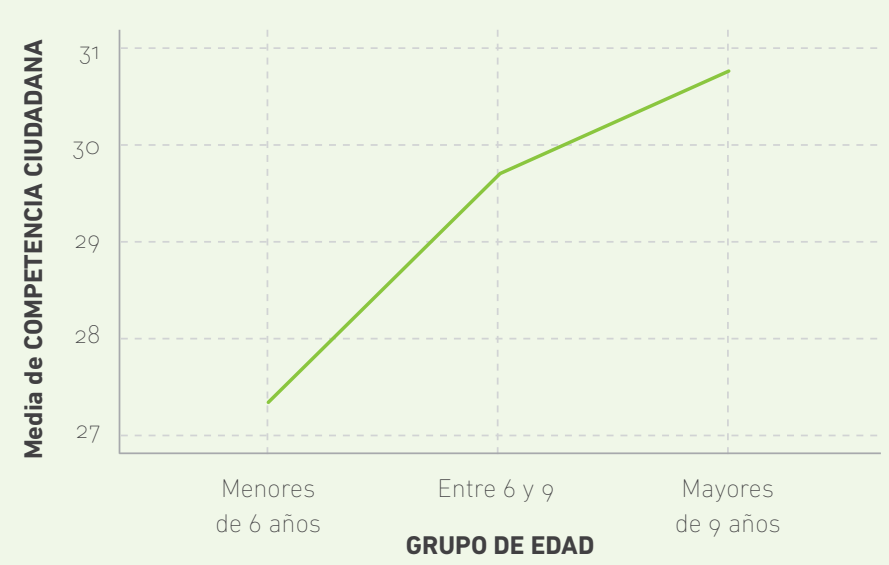

FIGURA 2. DIFERENCIAS EN EL DESEMPEÑO EN COMPETENCIAS CIUDADANAS POR

RANGOS DE EDAD EN NIÑOS QUE ASISTEN A LUDOTECAS EN LA LÍNEA BASE.

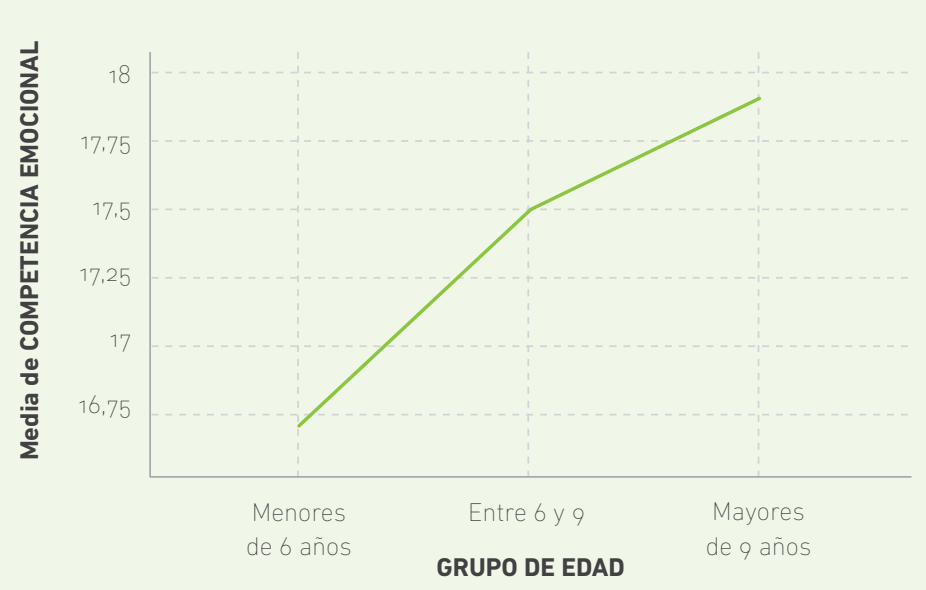

FIGURA 3. DIFERENCIAS EN EL DESEMPEÑO EN COMPETENCIAS EMOCIONALES POR RANGOS DE EDAD EN NIÑOS QUE ASISTEN A LUDOTECAS EN LA LÍNEA BASE. 


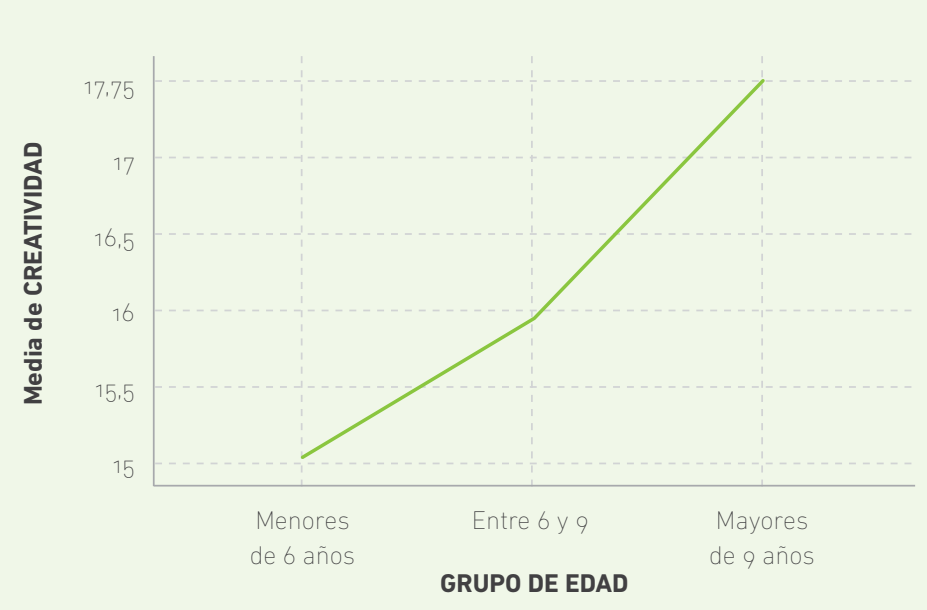

FIGURA 4. DIFERENCIAS EN EL DESEMPEÑO EN CREATIVIDAD POR RANGOS

DE EDAD EN NIÑOS QUE ASISTEN A LUDOTECAS EN LA LÍNEA BASE.

TABLA 12

ANOVA POR COMPETENCIA EN EL GRUPO DE NIÑOS QUE NO

ASISTEN A LAS LUDOTECAS EN LA LÍNEA BASE

\begin{tabular}{lccc}
\hline COMPETENCIA & $g l$ & $F$ & $p$ \\
\hline COMPETENCIA CIUDADANA & $(2,144)$ & 2.064 & .131 \\
\hline COMPETENCIA EMOCIONAL & $(2,144)$ & 1.576 & .210 \\
\hline CREATIVIDAD & $(2,144)$ & 3.136 & .046 \\
\hline
\end{tabular}




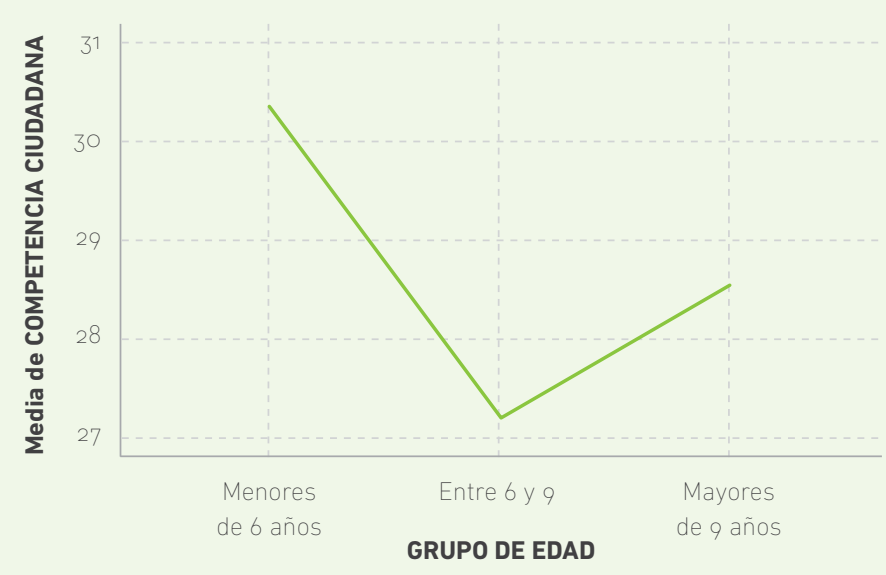

FIGURA 5. DIFERENCIAS EN EL DESEMPEÑO EN COMPETENCIAS CIUDADANAS POR

RANGOS DE EDAD EN NIÑOS QUE NO ASISTEN A LUDOTECAS EN LA LÍNEA BASE.

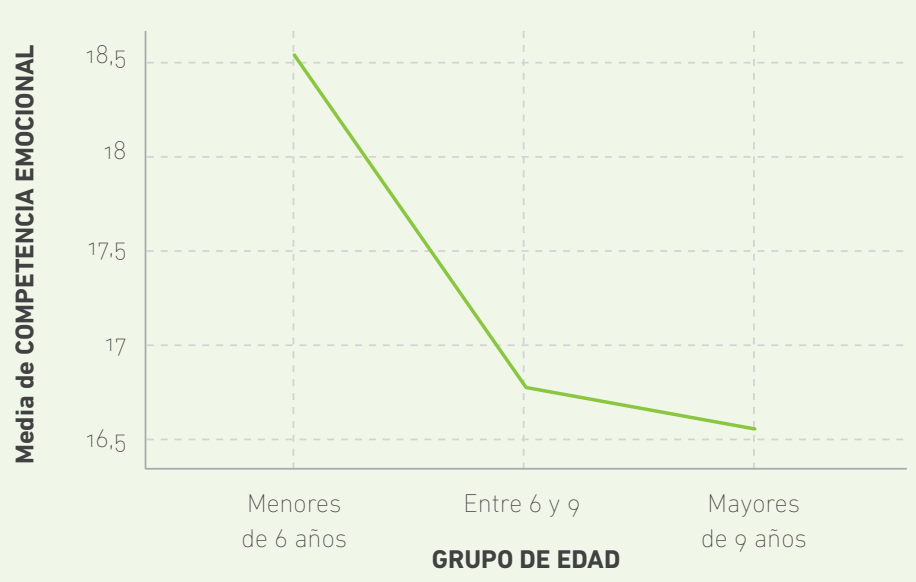

FIGURA 6. DIFERENCIAS EN EL DESEMPEÑO EN COMPETENCIAS EMOCIONALES POR RANGOS DE EDAD EN NIÑOS QUE NO ASISTEN A LUDOTECAS EN LA LÍNEA BASE. 


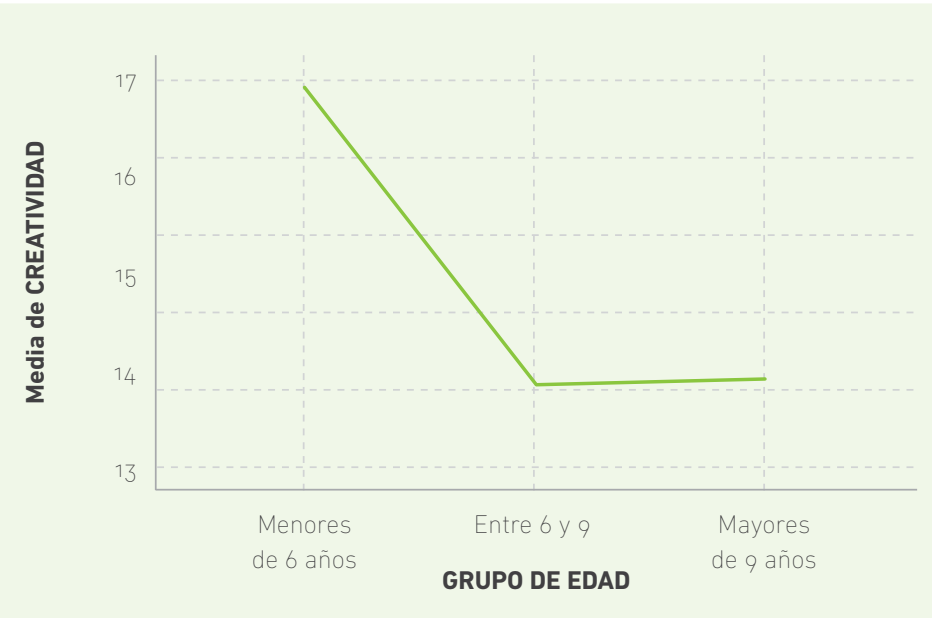

FIGURA 7. DIFERENCIAS EN EL DESEMPEÑO EN CREATIVIDAD POR RANGOS DE EDAD EN NIÑOS QUE NO ASISTEN A LUDOTECAS EN LA LÍNEA BASE.

\section{Conclusiones de la línea de base}

Los puntajes generales encontrados en este primer momento del estudio señalan impactos importantes del juego y las ludotecas, principalmente en las competencias ciudadanas y la creatividad y, parcialmente, en las competencias emocionales. Para el caso de las competencias ciudadanas, las diferencias con el grupo contraste resultaron significativas para participación y autonomía, convivencia, interacción en el juego y manejo de reglas. Las competencias emocionales que se vieron afectadas fueron expresión de emociones y empatía, y las de creatividad fueron pensamiento divergente, flexibilidad y elaboración. Lo anterior indica que estas competencias son las que posiblemente se ven más afectadas por la exposición a mayores situaciones de juego de niños y niñas en escenarios lúdicos. De igual forma, se encontraron diferencias significativas en las competencias entre grupos de edad, tendiendo a aumentar con el tiempo 
en los niños que asisten a estos escenarios, en comparación con quienes solo van a la escuela. Las competencias de estos últimos tienden a disminuir con la edad. En general, estos hallazgos muestran el posible impacto que tienen las ludotecas en el desarrollo ciudadano, emocional y creativo de niños y niñas a lo largo del ciclo vital.

Los resultados sobre la interacción en el juego eran apenas esperados. Diversos autores, como Marín (2009), Fleisher (2015) y Ringoot et al. (2013), ya habían señalado el efecto que tiene el juego sobre las capacidades de los niños de interactuar con los objetos y con los otros. Por otra parte, siguiendo a Benedet y Zanella (2011), y a Riquelme et al. (2013), suponemos que el manejo de reglas se ve afectado porque el juego implica tanto la comprensión de la existencia de reglas sociales como el reconocimiento de la importancia de cumplirlas. Al respecto de la convivencia, se confirma lo señalado por Mejía y Londoño (2011), en el sentido de que la exposición a escenarios de juego se convierte en pieza clave para la convivencia en sociedad. Por su parte, el efecto sobre la autonomía confirma lo señalado por Managers (2005) y Power (2011), en términos de que el juego podría permitirle al niño autoadministrar los recursos que se le ofrecen para la actividad lúdica, aumentando esta capacidad.

A pesar de estos hallazgos, aún no es muy claro el porqué de la poca diferencia en el manejo de conflictos entre niños que asisten a las ludotecas y el grupo comparación en este momento del estudio. Al respecto, se suscitan un par de hipótesis: por una parte, es posible suponer, debido a los puntajes (ninguno superior a 6 puntos), que para los niños partícipes de la muestra existe dificultad en dicha resolución. La otra hipótesis (la más probable para los investigadores), es que lo encontrado pudo deberse a una dificultad en la evaluación de la resolución de conflictos solo por medio de la observación de situaciones. La observación de esta competencia puede tornarse difícil en escenarios cons- 
tantemente mediados por reglas, como son los de las ludotecas. Al respecto, se requieren nuevos estudios que sean más sensibles al componente del conflicto y su resolución. Los estudios tradicionales sobre solución de conflictos en niños apelan a una observación más prolongada en escenarios familiares (Abuhatoum \& Howe, 2013); mientras que otros, por el contrario, se basan en el uso de cuestionarios a los padres (Weaver, Shaw, Crossan, Dishion, \& Wilson, 2015), o en otras técnicas basadas en el reporte de pares y en narrativas personales, como el Revised Class Play Method (Davidson, Walton, \& Cohen, 2013; Masten, Morison, \& Pellegrini, 1985).

Suponemos que la no diferencia significativa, general, en la competencia emocional, la cual es calculada como la suma de tres componentes, se atribuye a un efecto estadístico de arrastre del puntaje general por el componente de autorregulación, el cual no mostró diferencias significativas en este primer momento. Sin embargo, los análisis específicos señalan diferencias en la expresión de emociones y en la empatía. Estos resultados confirman lo señalado por Niec y Russ (2002) y Power (2011), en términos de los efectos positivos del juego sobre la empatía, especialmente a partir de juegos sociodramáticos. Por otro lado, sobre la expresión de emociones, es poco lo que los estudios mencionan en su relación con el juego. Siguiendo a Reed y Brown (2000), suponemos que esta llega a ser importante también en los juegos sociodramáticos. Los resultados sobre la regulación emocional, en este momento, aún son inciertos. Algunas teorías de la emociones y el juego sugieren que esta se ve influenciada significativamente durante el juego activo (LaFreniere, 2013). Sin embargo, y de acuerdo con la literatura, esta competencia es dependiente del desarrollo a largo del tiempo. El estudio longitudinal podría dar luces sobre cómo se ve afectada esta competencia por la exposición prolongada a escenarios lúdicos. 
El grupo de componentes en donde se encontraron mayores efectos fue en el de creatividad. Las relaciones entre juego y creatividad han sido ampliamente reportadas por la literatura (Holmes, Romeo, Ciraola, \& Grushko, 2015; Saracho, 2002). Por ello, se sabe que las actividades lúdicas ayudan al niño a adquirir competencias de conocimiento específico, a mantener la curiosidad y el asombro, lo que conduce a un mayor pensamiento creativo e imaginativo (Johnson, 2007).

Los resultados por género sobre las competencias ciudadanas muestran un mayor efecto de las ludotecas, especialmente en manejo de reglas en los niños, y en la participación e interacción en el juego de las niñas. Señalando, con ello, efectos interesantes sobre capacidades regulatorias o morales, y aumentando las capacidades sociales de las niñas. Los escenarios lúdicos también parecen tener un efecto importante sobre las competencias emocionales de los niños, más que de las niñas. Este impacto en los varones parece estar dirigido particularmente al desarrollo de la empatía. Los niños, más que las niñas, se ven afectados por los escenarios lúdicos en su creatividad, especialmente en la flexibilidad y en la elaboración.

Al comparar los desempeños en las competencias por grupos etarios, los investigadores nos encontramos con un hecho interesante del cual no teníamos referentes. Lo aquí encontrado muestra que, al parecer, la exposición prolongada a escenarios lúdicos, a lo largo del tiempo, parece tener un efecto significativo en los niños, especialmente sobre las competencias ciudadanas y la creatividad, lo cual sugiere que el juego puede tener un lugar importante en el proceso educativo infantil, particularmente superando los 6 años de edad, lo que daría pistas sobre el alcance de modificar las prácticas educativas para incorporar estos escenarios y estrategias lúdicas a la educación primaria y secundaria.

\section{| 94}


